\title{
TERRITÓRIO E PODER: SISTEMA, CONSTRUCTO E ALIENAÇÃO TERRITORIAL
}

\author{
Bianca Caroline Bortolin \\ Mestranda em Geografia, Instituto de Geociências e Ciências Exatas, Unesp, Campus de Rio Claro. \\ biabortolin@gmail.com \\ José Gilberto de Souza \\ Professor Associado do Departamento de Geografia, Instituto de Geociências e Ciências Exatas, Unesp, \\ Campus de Rio Claro. \\ ig.souza@unesp.br
}

\begin{abstract}
RESUMO
O artigo realiza uma análise sobre o nível de constructo e alienação territorial presente nos espaços agrários, a partir das práticas socioespacais e as relações de poder em seu conteúdo de classe. Investiga-se uma representação dessas relações, que não esteja circunscrita ao fechado sistema territorial. Elabora-se uma escavação teórico-conceitual e analítica das práticas socioespaciais dos sujeitos as quais compreendemos como resultantes em determinações territoriais que afirmam e/ou infirmam um processo de construção territorial. Compreende-se que em cada território há relações de poder que são próprias dos sujeitos e ocorrem, em simultaneidade, às relações de poder entre outros territórios e projetos societais. Essas práticas baseiam-se nas necessidades, nos projetos e nas intencionalidades dos grupos sociais que os habitam conduzindo a processos de identidade e/ou alienação territorial.
\end{abstract}

Palavras-chave: Território. Poder. Assentamentos rurais. Sistema territorial.

\section{TERRITORY AND POWER: SYSTEM, CONSTRUCT AND TERRITORIAL ALIENATION}

\begin{abstract}
The article analyzes the level of construction and territorial alienation present in agrarian spaces, based on socio-spatial practices and power relations in their class content. A representation of these relations is investigated, which is not limited to the closed territorial system. A theoretical-conceptual analytical excavation of the socio-spatial practices of the subjects is elaborated, which we understand that result in territorial determinations that affirm and / or infirm a process of territorial construction. It is understood that in each territory there are power relations that are specific to the subjects and that occur, simultaneously, to power relations between other territories and societal projects. These practices are based on the needs, projects and intentions of the social groups that inhabit them, leading to processes of identity and or territorial alienation.
\end{abstract}

Keywords: Territory. Power. Rural settlements. Territorial system.

\section{INTRODUÇÃO}

A fim de refletir sobre os elementos e os processos constitutivos de um território e das relações de poder que nele se materializam, buscou-se uma sistematização e representação dessas relações, tendo como recorte espacial o espaço agrário brasileiro, em específico as espacialidades que se representam formas de resistência à forma mercadoria. Entende-se que encontrar a essência das relações de poder existentes nesses espaços pode permitir a compreensão sobre seus fenômenos e sua reprodução, sejam eles favoráveis ou não ao exercício das territorialidades dos sujeitos. Objetivase analisar em que medida determinadas práticas podem chegar ao nível do constructo ou alienação territorial desses espaços agrários. Trata-se de um exercício teórico que representa aquilo que em Marx (1980) é definido como método de investigação seguido de sua exposição e, nesse caso, propomos um exercício intelectivo objetivando identificar (investigar) as determinações essenciais, considerando as relações de poder e seu conteúdo de classe.

Partiremos do que Raffestin (1993) define por espaço e território. Tal escolha de autor se dá por este ter sido um dos geógrafos responsáveis pelo resgate da categoria território nas análises geográficas, por suas reflexões que estão próximas do materialismo histórico, embora seu desenvolvimento 
ulterior carregue uma multiplicidade de aberturas epistemológicas (FULINO, 2020), mas duas coisas são centrais em suas reflexões: o território é um processo de apropriação do espaço na forma intelectiva (representação) e formal (trabalho), e as relações de poder são centralidade do constructo de um território.

Para o autor, o espaço é entendido como condição prévia para qualquer ação de existência e de trabalho humano, estando ambos inseparáveis tanto das iniciativas quanto das consequências destas ações: ele é [...] "'dado' como se fosse uma matéria-prima. [...] é a realidade material preexistente a qualquer conhecimento e a qualquer prática" (RAFFESTIN, 1993, p. 144). Raffestin baseia sua definição sobre espaço em Lefebvre ${ }^{1}$, entendendo-o como uma condição dada, de localidade e de materialidade, que pode ser modificada a partir do trabalho realizado sobre esse espaço, suas intencionalidades e suas consequências. A premissa de se entender o espaço a partir de sua materialidade se dá pelo fato deste ser a condição indispensável para a construção dos territórios. E, neste sentido, o autor nomeia de 'atores' paradigmáticos e sintagmáticos aqueles que agem sobre os espaços e que constituem os territórios.

O geógrafo franco-suíço afirma que, nessa condição de localidade e materialidade do espaço, haveria uma passagem de espaço para território e que este ocorre durante o movimento prático-analítico. Assim, para ele, "o território [...] é resultado de uma ação conduzida por um "ator" sintagmático em qualquer nível. Ao se apropriar de um espaço, concreta ou abstratamente, o ator 'territorializa' o espaço" (RAFFESTIN, 1993, p. 143). O autor amplia a análise do processo de produção e constituição dos territórios usando a perspectiva relacional e aponta que o Estado não é a única fonte de poder, e que este também não pode ser tomado como seu sinônimo².

Importante relembrar que a Geografia inicia a abordagem territorial em Ratzel (século XIX), por meio de uma sistematização que se sustenta nas necessidades centrais de reprodução humana (alimentação e habitação) e que se amplia para a formação do Estado, em uma perspectiva nomotética na Teoria dos Espaços Crescentes ou as Leis da Formação do Estado. Trata-se de um recurso epistêmico sobre o qual o autor realiza os desdobramentos analíticos de compreensão do espaço/território como demanda fisiológica do Estado (espaço vital - Lebensraum) (RATZEL, 2011).

A título de registro, cabe considerar que as contribuições do geógrafo Claude Raffestin, segundo Fulino (2020), não se estabelecem como hegemônicas na Geografia francófona. Seus estudos são, em primeiro lugar, recebidos na Itália, nos Estados Unidos e Inglaterra e refletem uma disputa teóricopolítica realizada com Ives Lacoste, acerca do Estado como lócus central de poder e suas dimensões relacionais, defendidas por este autor, e que revelam influências do pensamento filosófico de Michael Foucault.

Considera-se, nesse debate, que as duas posições (Lacoste e Raffestin) passam a construir uma análise crítica à Geografia Clássica francesa e à busca de novas perspectivas teóricas e metodológicas. Por sua vez, o pensamento de Raffestin, como aponta Fulino (2020), reúne um conjunto importante de elementos críticos para a Geografia sem, no entanto, desvencilhar-se das mesmas armadilhas teóricas que o contrapõe. Em que pese, Raffestin busca nesse processo uma caracterização quantitativa para a consolidação das relações de poder, além de uma estrutura nomotética sustentada na linguística como parâmetro epistemológico (FULINO, 2020) para representação destas.

Por sua vez, a dimensão relacional de Raffestin passa a fundamentar várias concepções e reflexões críticas sobre o território, que reconhecem as relações de poder como assimétricas (CASTRO, 2009), ou mesmo reflexões mais centradas no materialismo histórico, expressando sua dimensão de classe, como afirma Oliveira (1996):

(...) Para nós, o território deve ser apreendido como síntese contraditória, como totalidade concreta do processo / modo de produção / distribuição / circulação consumo e suas articulações e mediações supra estruturais (políticas, ideológicas, simbólicas, etc.) onde o Estado desempenha a função fundamental de regulação. É,

\footnotetext{
1 LEFEBVRE, Henri (1978 apud RAFFESTIN, 1993, p.143-144).

2 Neste aspecto, Raffestin distancia-se das concepções de Ratzel (o qual utiliza o território como categoria analítica e é resgatado pela geografia dos anos 1970 e 1980) para o qual é apenas no e pelo Estado que se exerce e se observa o poder, demonstrando a partir de relações de oposição entre centro e periferia, interior e exterior, superior e inferior (RAFFESTIN, 1993, p. 16).
} 
pois, produto concreto de luta de classe travada pela sociedade no processo de produção de sua existência. Sociedade capitalista (...). Dessa forma, são as relações sociais de produção e processo contínuo/contraditório de desenvolvimento das forças produtivas que dão a configuração histórica específica ao território (OLIVEIRA, 1996, p. 7).

Significa dizer que a terra em si, sua posse ou propriedade, não expressa a dimensão territorial, mas sim uma primeira condição para tais processos. Logo, são as práticas socioespaciais - decorrentes das interações entre sujeitos sociais e terra - que estabelecem o constructo. O ponto de apoio reside na compreensão de que o poder é relacional e que seu reflexo sobre o espaço formaria o território, não sendo este constituído a priori e não se equivalendo apenas a uma idealização dos sujeitos. O território é então determinado por ações concretas e pelas práticas socioespaciais, que dão sua configuração (SOUZA, 2009). Consubstancia-se, dessa maneira, em uma materialidade a partir das práticas socioespaciais dos sujeitos.

Como atributo central, o território pode ser considerado como categoria empírica ou analítica, pois:

[...] ele sempre surge como resultado de um campo específico de relações, com referência às relações sociais de poder, onde quer que estejam os sujeitos concretos e suas representações e, neste processo, o território deixa de ser um conceito em-si, que explica (se foi possível ser) para se tornar um fenômeno per-si (para o sujeito), que exige uma explicação (SOUZA, 2009, p. 109).

A problemática posta é que o conjunto de práticas socioespaciais dos sujeitos conformaria dinâmicas, ações e reações existentes nos e entre os territórios, particularmente, nos movimentos sociais. A constituição dessa configuração socioespacial é estabelecida no movimento de contradição de luta e ocupação da terra, somado ao de luta pela sua permanência. Assim, considera-se imanente a passagem, a processualidade histórica da terra ao território, como fundamento de constituição desses espaços de luta e, neste sentido, é possível constatar uma intencionalidade (SOBREIRO FILHO, 2015), a qual permite alçarmos ao conceito de teleologia dos sujeitos sociais em sua trajetória histórica.

\section{Poder como substância para as relações e territórios}

$\mathrm{Na}$ ação dos homens sobre o espaço imprime-se uma prática de apropriação, com determinações oriundas das relações de poder. Há uma dimensão teleológica que se materializa no enfrentamento de disputa pela terra, por exemplo, e que exige um segundo movimento para a constituição socioterritorial. Trata-se efetivamente do processo metabólico de produção ou degradação de territórios pelos sujeitos sociais na sua relação com a natureza e consigo mesmos. Um processo que situa a conformação territorial enquanto classe e homem genérico. Esse processo determina a dimensão ontogenética do território sem impor a priori sua perspectiva classista (SOUZA, 2014), uma vez que as práticas socioespaciais podem estar eivadas de processos de alienação. Como nas palavras de Sartre em Crítica à Razão Dialética: "[...] a prática individual, façamos o que fizermos, realiza a cada um o ser de classe" (SARTRE, 2002, p. 113).

Os territórios, como expressões geográficas do poder, indicariam o nível de constructo que as práticas socioespaciais dos sujeitos estabelecem e que se coadunam com suas formas de reprodução social. Os constructos podem ser materiais (se revelam pela condição material de existência) (KOSIK, 1969; MARX, ENGELS, 2007) e imateriais (como representação social, consciência material) (MOSCOVISK, 2010; KOSIK, 1969).

Nesta imbricada relação entre prática e consciência é que emerge o conceito marxista de alienação e, nesse sentido, cumpre-nos compreender que "[...] nos domínios da infraestrutura da alienação, quer dizer, no plano da alienação econômica, para utilizar os resultados aí obtidos num outro plano, isto é, na observação das outras formas e aspectos do fenômeno" (KONDER, 2009, p. 45) é que se materializam condicionantes de alienação territorial (matéria e consciência). Significa dizer que em contraposição ao exposto, no efetivo movimento de tomada da terra emergem os condicionantes de um constructo de caráter ontogenético e que podem se realizar em "povo"3 e ou classe para si.

\footnotetext{
3 Nossa reflexão se fundamenta nas experiências dos movimentos de retomada dos povos originários (particularmente do Guarani Kaiowa) que, embora vivenciam um embate de classe (disputa de terra-território
} 
(SOUZA, 2009; 2014), nesse embate se apresentam os germes de um constructo territorial. Tais germes não estão dados, pois possuem a capacidade de romper os domínios de infraestrutura e da alienação e demarcar outras formas de existência na sociedade.

Essas práticas socioespaciais, portanto, os fazeres humanos, como assinala Sartre (2002), os "resultados obtidos" (econômicos) e as outras formas de realização do ser, que aponta Konder, são passíveis de sistematização e representação, permitindo identificar as dimensões teleológicas dos sujeitos. Nesse processo, há de se considerar e especificar quais práticas socioespaciais seriam de ação comum aos territórios de resistência nos espaços agrários brasileiros, sejam para um constructo territorial ou para uma alienação territorial (QUAINI, 1979).

Sendo assim, a sistematização e representação destas práticas socioespaciais, possibilitam análises sobre tais espaços de conflito e seus núcleos de poder, consolidando em uma representação cartográfica:

Observa-se que nos níveis máximos de identificação das relações e práticas socioespaciais contíguas se revelam os limites e nas não contíguas as tessituras, na medida em que nos distanciamos da centralidade, dos núcleos que emanam o poder, é possível determinar as dimensões zonais/areolares e/ou os limites cartograficamente expressos. Importante assinalar que ao se distanciarem desse núcleo provedor, paulatinamente tendem a perder a "forma", mesmo assim "exige-se" que as "fronteiras/limites" sejam expressas, no rigor de representação, por uma "linha tracejada", como "medida" daquilo que já transparece como fluidez das determinações no espaço/território (SOUZA, 2016, p. 59).

Significa dizer que, de acordo com as práticas socioespaciais, vão se constituindo determinações territoriais que configuram uma identidade social ao espaço, e a questão central é em que medida a alienação, a cooptação e a submissão podem ser elementos (mediadores de relação de poder) que se colocam em oposição ao projeto social daquele movimento social.

Neste aspecto, em que os sujeitos sociais dão o sentido constitutivo ao território, é que surge a primeira absonância em relação ao pensamento de Claude Raffestin. O autor distingue dois tipos de atores sociais: os sintagmáticos e os paradigmáticos. $\mathrm{O}$ ator sintagmático, para o autor francês, é aquele que detém um "programa" e que determina tal projeto teleológico ao ator paradigmático, sendo então aquele que executa tal projeto. Ao buscar referenciais na linguística (sintagmático e paradigmático), o autor se esquece que o determinante de um projeto (sintagmático) executa sobre outrem uma ação comunicativa e que este, por sua vez, apenas replica. Nesse sentido, aquele que o replica não realiza processos mediadores, reflexivos e, nesse caso, só podem ser-estar determinados por um estágio de alienação. A ilustração representa, portanto, que um ser ${ }^{4}$ paradigmático executa o projeto de outrem, o que significa que ele atua em uma espacialidade sobre a qual intencionalmente ele não detém poder. Evidenciando que Raffestin estabelece uma prisão para estes sujeitos sociais, sem refletir em que bases ela está dada e sobre quais circunstâncias estes sujeitos alienam suas vontades (intencionalidades), por conseguinte, sua determinação territorial.

Uma segunda dissonância se refere ao conceito de poder. Sendo o território então o resultado de uma ação ${ }^{5}$ sobre o espaço, sua produção ocorre a partir de um campo de poder, no qual se dão as relações entre homem-homem, homem-sociedade, homem-espaço e sociedade-espaço. Para o autor, há uma diferença no uso dos termos Poder e poder (o primeiro, diretamente vinculado às ações dos Estados, como legitimação dada pela sociedade; e o segundo como aquilo que sustenta as relações entre os homens e as instituições). Entretanto, compreende-se que o poder existe a partir de mediações distintas dos sujeitos em relação ao mundo, tendo ou não instituições mediadoras (o Estado, por exemplo), e não necessitam de uma separação semântica ou de um sentido conotativo.

com os latifundiários e capitalistas), sua estratégia de resistência não se caracteriza como classe. Esse processo requer analisar a dimensão teleológica dos povos originários e seu desenvolvimento ulterior em um contexto de não classe (povo) $x$ classe.

${ }^{4}$ Cabe reafirmar que não utilizamos o termo "ator" porque compreendemos que se tratam de sujeitos sociais que realizam sua vida cotidiana nas espacialidades, e não uma representação, uma encenação de vida.

${ }^{5}$ Nesse sentido, compreendemos ser uma tautologia o conceito de "território usado". 
Para analisar os territórios, é necessário explicitar as relações que nele ocorrem, suas correspondências interterritoriais e suas multiescalaridades ${ }^{6}$.

Preocupada com o rigor das terminologias e dos conceitos, Castro (2009) considera que o termo poder não deva ser utilizado de forma banal, sendo entendido como algo dado ou natural. O poder só existe porque há relações, e estas, em sua maioria, ocorrem de maneira assimétrica. Segundo Raffestin (1993, p. 53), o poder é "[...] um processo de troca ou de comunicação quando, na relação que se estabelece, os dois polos fazem face um ao outro ou se confrontam. As forças de que dispõem os dois parceiros criam um campo: o campo do poder"7. Ainda, na perspectiva de centralidade do poder no Estado, Becker (1983, p. 1) enfatiza que o "[...] desenho [do território] é consequência da relação de poder entre Estados", podendo ser uma referência à interpretação proposta por Ratzel, que parte de uma perspectiva na qual ao Estado restaria apenas a função de consolidação e defesa de seus limites e fronteiras, e teria como composição elementos analíticos (população, área total, existência de recursos e quantidade destes, entre outros).

Entretanto, a autora não evidencia a existência de uma relação direta entre o exercício do poder e os Estados, como o espaço-vital proposto pelo autor alemão e sua Teoria dos Espaços Crescentes, relacionando diretamente Estado, solo e território; o que poderia atribuir-lhe uma significação espacial e "teorizá-lo" geograficamente (RAFFESTIN, 1993, p. 15). Becker utiliza outros elementos para a construção do tema, como o poder e suas relações. Para a autora, "[...] o aparelho governamental não é o instrumento único do Poder", sendo ele apenas um dos elementos de infraestrutura para a ação de outros sujeitos sociais, que também fazem usufruto das relações de poder, como o capital e a tecnologia. Já o território é pensado a partir de uma dialeticidade, ele é "[...] um produto 'produzido' pela prática social, e um produto 'consumido', vivido e utilizado como meio, sustentando, portanto, a prática social” (BECKER, 1983, p. 6-8). Para essa questão seremos suscintos. O Estado não se caracteriza como uma instância em separado da sociedade, trata-se de uma instituição que gere e vitaliza as formas de realização do valor. A dimensão do Estado como ente de defesa, de configuração imagética de área de poder, cria uma ideação que anula seu caráter de classe.

Para Castro (2009), existem alguns empecilhos às interpretações e trabalhos que relacionam espaço e poder e que têm como consequência um território: ou por tratarem os espaços sendo eles os atores das relações; ou por acordar que os atores são, de fato, os sujeitos que se territorializam e criam relações de poder em espaços assimétricos; sujeitos esses ligados direta ou indiretamente aos territórios. Salientamos que nosso posicionamento recai sobre a segunda condição, a de que os sujeitos são os responsáveis pela existência das relações de poder e que estas não são abstratas, aleatórias ou naturais; mas mediam as condições internas e externas, e suas práticas e representações sobre os espaços e constituem territórios, revelando suas determinações, que expressam elementos de hegemonia ou de resistência, uma contra hegemonia.

Assumimos, portanto, que as práticas socioespaciais dos sujeitos se materializam em determinações territoriais. Para Borges e Souza (2019), as determinações territoriais são "estado", entendido como situação de um dado fenômeno, e "movimento", sendo a direção, a intencionalidade, uma "processualidade histórica", uma teleologia de sujeitos e classes sociais em busca da hegemonia; de seu projeto político-societal, que se imprime no espaço, estabelecendo, então, o constructo territorial. As práticas socioespaciais dos sujeitos produzem processos que permitem distintos constructos territoriais e/ou sua negação, ao que denominamos de alienação territorial.

\footnotetext{
${ }^{6}$ Lacoste (1988) observa o problema epistemológico da escala na Geografia. Multiescalaridade não implica em sobreposição métrica de espacialidades, mas sim no sentido em que as relações sociais de poder extrapolam e se interrelacionam com diferentes níveis espaciais e, simultaneamente, ganham novos sentidos de representação, inclusive cartográfica, diante da força epistêmica e/ou capacidade explicativa que a análise mantém sobre o fenômeno. A escala não é a expressão por si só do fenômeno, mas é também das determinações territoriais e suas transformações. Souza (2016, p. 59) adverte que a "escala posiciona os sujeitos sociais (e o pesquisador) frente à questão que está posta e permite a real construção dos recortes espaciais necessários à resposta. Assim, é preciso compreender que a escala é, ao mesmo tempo, um recorte, uma representação e uma análise. Uma expressão espacial que demonstra e revela os níveis de entendimento".

7 Castro e Raffestin constroem sua linha de pensamento a partir da obra História da sexualidade: a vontade de saber, de 1976, de Michel Foucault, que, como elencado por Raffestin (1993, p. 53), definiu as condições para que as relações de poder ocorressem: (a) o poder se exerce; (b) é efeito das relações desiguais existentes em outras relações; (c) o poder existente emana desde as camas de baixo, das famílias, das relações entre os sujeitos; (d) essas relações são intencionais e (e) se existe poder, existe resistência a ele.
} 
Considerando então este movimento, a perspectiva relacional rompe com uma possível dimensão estática tanto do território quanto do próprio Estado, trazendo para esse processo as relações sociais e o que há de imanência nelas, o movimento e a existência de contradições; elementos que são essenciais para a análise da trajetória humana no mundo e, por sua vez, de seus modos sociais e de produção.

O território é, então, produto da ação do homem sobre o espaço e, entendendo que a sociedade capitalista se constitui a partir das relações de classe - desiguais e contraditórias - a produção territorial materializar-se-ia pelas relações de poder entre as classes, entre seus projetos hegemônicos e suas formas de resistência. Configuram-se aí os campos do poder (RAFFESTIN, 1993), permitindo, assim, observações, representações e análises dessas relações, que são tanto de poder, como de classes sociais.

Outro elemento a ser considerado na formação e, posteriormente, nas análises sobre os territórios é a hegemonia e seu exercício. Aqui entendemos este conceito a partir das definições dadas em uma perspectiva gramisciana que, segundo Alves (2010, p. 78), "[...] pressupõe que se leve em conta os interesses dos grupos sobre os quais a hegemonia será exercida, que estabeleça uma relação de compromisso [filosóficos e políticos]". A ação hegemônica deve ser um elemento central na análise do constructo, na medida em que revela o projeto da classe que está na organização e efetivação das práticas socioespaciais, mas que está sempre mediado pelos condicionantes de um bloco histórico.

Entendendo a indissociabilidade entre o exercício do poder e a criação de territórios, as análises sobre o grau de hegemonia existente nas relações permitirão a representação desses modos de vida e de produção, dos conflitos entre as classes, ou de outros projetos societais, como dos povos originários. Dessa forma, elencar elementos que podem colaborar com tais análises é considerado o primeiro passo para que as relações no e entre os territórios sejam compreendidas e analisadas.

\section{Decisões metodológicas}

Como asseveramos, o método em Marx (1980) é constituído de dois momentos/movimentos investigação e exposição (MULLER, 1983). O primeiro movimento se refere ao esforço inicial de apropriação, pelo pensamento, das determinações de conteúdo do objeto-processo, sobre o próprio objeto-processo e as condições materiais nas quais reconhecemos seu enfrentamento e processualidade histórica. Trata-se de uma apropriação analítica, reflexiva, antes mesmo de sua exposição metódica.

O segundo movimento, a exposição, não se refere a autoexposição que se autonomiza em abstrato ou acrítico, mas trata-se de uma análise crítico-objetiva do objeto em suas contradições, esclarece Müller (1983). Para Marx (1980), a exposição é uma tradução do movimento efetivo real, espelhando o real no ideal. Trata-se de uma reprodução, no sentido de uma reconstrução crítica do objetoprocesso. De acordo com o autor, a construção desse método dialético sempre requer um trabalho prévio de investigação ("escavação" e "garimpo"), de sua captação com detalhes, de suas formas de evolução, de suas conexões, para depois expor adequada, sistemática e criticamente a sua lógica, demonstrando suas dinâmicas internas, seus limites e contradições.

Nesse sentido, o que apresentamos neste texto é o movimento de investigação, uma escavação teórico conceitual sobre as práticas socioespaciais e em que medida elas conduzem aos projetos sociais distintivos do capital. Não se trata de uma idealização, mas se fundamenta na base teórica de reflexões críticas produzidas no campo das Ciências Humanas e Sociais, daí a necessidade de construção coesa e coerente do estado da arte, aproximada de uma perspectiva teórica: o materialismo histórico.

Admite-se o método de investigação a partir de uma reflexão acerca de categorias e conceitos que denotam capacidade explicativa sobre a realidade. Elas são elencadas considerando os aportes teóricos centrais que buscam explicitar as relações sociais de produção, a estrutura econômica e social dos assentamentos e suas interfaces com as formas capitalistas de produção do valor.

Para tanto, a posição tomada nesse processo de escavação tem como condição a exposição dos conflitos de classes existentes no sistema capitalista, em específico as relações que são diretamente ligadas aos espaços agrários; mostrando condições já extensamente debatidas de exploração da 
terra na lógica da mercadoria (ou como meio para uma tríade de processos de acumulação) a subsunção formal e real do trabalho (exploração da mais valia e os processos de controle pela desigualdade e sua extensão ao desenvolvimento das forças produtivas), a sujeição da renda da terra ao capital (exploração do trabalho camponês pelo processo mercantil de sua produção) e da expropriação e espoliação (acumulação primitiva) da terra como meio de existência de comunidades indígenas, quilombolas ou camponesas e, por último, como essa tríade muda qualitativamente ao ser mediada pela lógica de financeirização, da reprodução do valor e do autovalor.

Deixando claras nossas questões de método, cumpre considerar a origem e uso conceitual de sistema na Geografia, uma vez que, mesmo sem relação direta, Raffestin emprega tal nomenclatura em seu trabalho.

\section{O sistema territorial de Claude Raffestin e a perspectiva de constructo e alienação territorial}

Utilizada inicialmente nas análises de Geografia Física, a ideia de sistema foi adaptada da Teoria Geral dos Sistemas (TGS), criada na década de 1930 por Bertalanffy (1973) e ganhou expressividade pelos trabalhos do geomorfólogo Sotchava (1977). Os trabalhos partiam da compreensão do mundo natural como se este fosse um sistema fechado, embora, para o autor russo, havia uma busca incessante de demarcar as condições de reprodução humana como necessárias ao entendimento dos movimentos das dinâmicas geomorfológicas.

No Brasil, os precursores no uso desse conceito foram Christofoletti (1979) e Troppmair (2000). As contribuições oriundas do uso da TGS nas análises geográficas aprofundaram e sistematizaram o conhecimento sobre os compartimentos geomorfológicos. Entretanto, o seu uso exclusivo ou solitário não permitiu que as análises levassem em consideração criticamente outros fatores que compõem um sistema geomorfológico, como as ações antrópicas, as imbricações de suas formas de apropriação do espaço e as dinâmicas da superfície terrestre. A não inclusão de análises mais complexas e que contemplem o corpo social presente sobre as estruturas geomorfológicas em muito se aproximaram das análises naturalistas do final do século XIX e início do século XX, trabalhos compostos por métodos lineares de descrição (pautados na observação), desconsiderando a não linearidade das relações sociais e de uso e exploração, apropriação da natureza.

Diante do exposto, apontamos as dificuldades de transposição desse conceito para as práticas socioespaciais dos sujeitos como determinações de afirmação e infirmação (negação) do constructo territorial. Nesse sentido, cabe estender nossas considerações críticas à proposta de sistema territorial de Raffestin em Por uma Geografia do Poder.

O sistema territorial se relaciona diretamente às territorialidades vividas, percebidas e concebidas nos espaços, revelando escalas e dimensões das relações de poder existentes (RAFFESTIN, 1993). Para o autor, as representações dos espaços são sua imagem e vão além dos pontos considerados de exercício de poder: a própria imagem ou representação produzida sobre o espaço expressa ${ }^{8}$ as relações de poder. Considerando que as relações sociais são assimétricas - resultam das relações de poder e se alteram a cada mudança de sua direção - os territórios construídos, concomitantemente, não são necessariamente fixos. Sua "tradução", sistematizada ou não, também é instável; logo, pode atuar sobre a afirmação ou negação desses poderes representados. Para o autor,

O sistema é tanto meio como um fim. Como meio, denota um território, uma organização territorial, mas como fim conota uma ideologia da organização. [...] Como objetivo, o sistema territorial pode ser decifrado a partir das combinações estratégicas feitas pelos atores e, como meio, pode ser decifrado por meio dos ganhos e dos custos que acarreta para os atores. O sistema territorial é, portanto, produto e meio de produção (RAFFESTIN, 1993, p. 158).

O sistema territorial é apresentado como produto, porque seu desenvolvimento é resultado de ações e relações de poder entre os sujeitos (atores) sobre o espaço, constituindo os territórios; e como meio por ser condição prévia e necessária para manter ou alterar as relações de poder - mudando ou não

\footnotetext{
${ }^{8}$ Como exposto por Yves Lacoste em "A Geografia: isso serve, em primeiro lugar, para fazer a guerra", publicado em 1976.
} 
a lógica capitalista de produção e transformação de todas as coisas em mercadorias - que ocorrem sobre os espaços e, assim, se constroem novos territórios.

Esses fenômenos necessitam de novas representações a cada movimento, reorientando as formas possíveis de exposição dos elementos - tessituras, nós e redes; bem como as distâncias econômicas, temporais, psicológicas e físicas - que foram elencadas por Raffestin (1993) como componentes do sistema territorial. Segundo o autor, "[...] não se trata de uma geometrização da ação, mas antes de uma ação que se procura representar geometricamente" (RAFFESTIN, 1993, p. 149). Assim, a dimensão objetiva do território, como projeto ou fim, expressa a intencionalidade dos sujeitos sociais no seu processo de consolidação territorial, que se materializa em territorialidades, território imaterial (FERNANDES ,2005), dimensão de consciência e/ou representação do território.

No entanto, para Raffestin (1993), essa representação não pode ser concebida apenas como da territorialidade. Ela é também território, uma vez que a territorialidade é uma dimensão do vivido relacional; e busca um modelo axiomático para sua demonstração, como:

(...) a soma das relações mantidas por um sujeito com o seu meio. Isso dito não se trata de uma soma matemática... [sic]... mas de uma totalidade de relações biossociais em interação", que se expressa na fórmula $\mathrm{T} \rightarrow \sum \mathrm{H} \mathrm{E}, \mathrm{H}$ sendo o indivíduo, o sujeito, desde que pertença a uma coletividade; $r$ sendo uma relação particular definida por uma forma e um conteúdo e que necessita de mediatos; e $E$ sendo a exterioridade, isto é, uma "topia", um lugar, mas também um espaço abstrato, como um sistema institucional, político ou cultural por exemplo (RAFFESTIN, 1993, p.160).

Complementa o autor que:

a vida é feita de relações, e daí a territorialidade pode ser definida como um conjunto de relações que se originam num sistema tridimensional sociedade - espaço tempo em via de atingir a maior autonomia possível, compatível com os recursos do sistema. Então a territorialidade pode ser assim expressa: $T \rightarrow \sum \mathrm{H} \mathrm{E}$ (RAFFESTIN, 1993, p. 160).

A dimensão axiomática de Raffestin parte de uma problemática que é concebida de forma abstrata, não estão dadas as relações concretas relacionais. Tal problemática é uma narrativa de pesquisa, e não a condição material de existência dos sujeitos (atores), como observamos sobre a determinação semântica dos "atores sintagmáticos e paradigmáticos". De forma que as relações são dadas por indivíduos e há uma passagem posterior, no âmbito da territorialidade, como expressão espacial de uma dada sociedade. Seria possível essa transição se o autor estivesse partindo de um ser social (LUKACS, 1979), e não de indivíduos. Assim, tanto quanto os atores e suas relações, a sociedade (abstrata) em suas relações satisfaz suas necessidades num determinado momento - em um local, exercendo uma carga demográfica e um conjunto de instrumentos também determinados de energia e informação. Ou seja, a transposição de relações de indivíduos para grupos sociais se estabelece em um abstracionismo, mas sem deixar clara como se estabelece.

Nesse modelo a territorialidade passa a ser um recurso, considerando que energia e informação (poder), para Raffestin, são os elementos básicos de constituição e relação entre territórios. O trabalho sintetiza energia e formação, configura o poder sobre um espaço (representação e ação), mas ao final passa a se configurar como um recurso, e não um processo metabólico de hominização e humanização, um recurso que depois se constituirá em força (de Estado, inclusive), como população.

Este conjunto de elementos demonstra a dimensão "discursiva", de "retórica", abstrata, que o autor assume ao projetar-se em um encadeamento de logicismos que se inscrevem em um sistema idealizado de relações e processos, tais como:

Toda produção do sistema territorial determina ou condiciona uma consumação deste. Tessituras, nodosidades e redes criam vizinhanças, acessos, convergências, mas também disjunções, rupturas e distanciamentos que os indivíduos e os grupos devem assumir. Cada sistema territorial segrega sua própria territorialidade, que os indivíduos e as sociedades vivem (RAFFESTIN, 1983, p. 161). 
Tais reflexões se vinculam a um "lugar comum", de "considerações óbvias" que não refletem de maneira concreta e material as condições sociais de reprodução e, portanto, cabem a qualquer condição explicativa porque derivam de idealizações sobre a vida humana.

Dessa forma, ao representar territorialidades (em suas esferas sociais, econômicas, políticas, culturais e ambientais, por exemplo), estas revelariam como as relações de poder se manifestam nesses espaços, permitindo assim uma observação dessas relações. Mas, sobre quais relações? Qual a capacidade de determinação histórica e em quais condições concretas de relações estabelecidas? Observa-se que, após estabelecer considerações à concepção de territorialidade de Edward Soja (1971) afirma que "o inconveniente do método de Soja é que ele mistura o subjetivo e o não-subjetivo e apaga as situações de classe" (RAFFESTIN, 1993, p. 162). mas, em verdade, esse mesmo processo se realiza em seus modelos ideais axiomáticos relacionais.

Esses modelos se apresentam em vários momentos no texto de Raffestin. Verifica-se que, ao estabelecer críticas à perspectiva morfofuncional da Geografia Política de Estado e apresentar alguns pressupostos de uma Geografia relacional de poder (particularmente nos capítulos I e II), tinha-se como expectativa que o autor desenvolvesse a proposta em termos de sistematizar práticas socioespaciais que concorreriam na demarcação de relações sociais de poder e configuração territorial. No entanto, seu movimento teórico, contraditoriamente, debruça-se sobre as mesmas categorias que dão suporte à Geografia Política de Estado: população, recursos naturais, língua, entre outros. Nesse conjunto passa a demonstrar modelos axiomáticos relacionais idealistas, particularmente, no capítulo III (O poder, no subitem III, o Campo do Poder). Seus enunciados, ou axiomas, são precedidos de figuras (gráficos) com os pontos e suas interconexões seguidas de algumas explicações:

A troca ou a comunicação que tem lugar entre a $A$ e $B$, se a relação atinge seus objetivos, pode se traduzir por ganhos e/ou custos para os dois ou para um deles. A relação pode ser simétrica ou dissimétrica, com ganhos e/ou custos tendo bem entendido, consequências sobre o quadro de referência respectiva dos atores, na medida que os elementos que contêm são afetados. Temos aí quatro atores $A, B, C$, $D$, em situação relacional. Admitamos por convenção que a flecha indica um custo para um ator em que ela se origina e um ganho para aquele no qual termina. A primeira observação que deve ser feita é que o gráfico não indica todas as relações possíveis. O número de relações possíveis é $m(m-1)$, isto é $4(4-1)=12$. Nesse gráfico só há a representação de quatro relações. Quando as analisamos...[sic]..., constatamos que há, em todo caso, três relações dissimétricas absolutas - C- A., A.D e D.C. - uma relação simétrica ou dissimétrica relativa - A.B. - e uma outra B.A. Para determiná-la precisaríamos atribuir um valor aos arcos. (RAFFESTIN, 1993, p. 61-62).

Esses exemplos axiomáticos (que podem ser idealistas, a depender do método utilizado para estudo da proposta) relacionais em nada apresentam elementos constitutivos analíticos, nem mesmo às problemáticas estabelecidas sobre população, recursos, entre outros elementos sobre os quais o autor se debruça nos capítulos posteriores.

No âmbito de um sistema territorial, Raffestin (1993) parte então da representação daquilo que define como sendo os elementos desse sistema (tessitura, nós e redes). A representação se realiza antes mesmo do problema, como elementos dados e, para nós, este é o problema:

A partir de uma representação, os atores vão proceder à repartição das superfícies (tessituras), à implantação de nós e à construção de redes. É o que se poderia chamar de 'essencial visível' das práticas espaciais, ainda que malhas, nós e redes não sejam sempre diretamente observáveis, pois podem pura e simplesmente estar ligados a decisões. Mesmo que não sejam discerníveis, têm uma existência com a qual é preciso contar, pois intervêm nas estratégias (RAFFESTIN, 1993, p.150).

Observa-se que, em verdade, o modelo analítico que sustenta as proposições de Claude Raffestin é a Cartografia. O que o autor espelha em sua análise são os processos de implantação areolar, pontual e linear. A cartografia como método de representação é assumida como modelo analítico e há, nesse caso, uma inversão entre exposição e investigação. A representação cartográfica configura-se em um produto do mapeamento das práticas socioespaciais, mas ela não as explicita no conjunto das contradições sociais. A cartografia é um texto e não um método. Como texto é um elemento explicativo do autor sobre dada realidade, ele expressa uma realidade, cuja técnica 
evidentemente precisa ser metodologicamente apreendida e explicitada pelo pesquisador A cartografia expressa a característica espacial do fenômeno segundo uma escala e uma distinção categorial e conceitual do pesquisador (SOUZA, KATUTA; 2001).

A questão é que Raffestin passa a discorrer explicações sobre as estruturas cartográficas (ponto, linha e área) como informações, mas que, em verdade, configuram-se apenas uma linguagem (uma narrativa) (cartográfica), uma representação constitutiva de uma imagem, mas que não está dada, porque não há uma pergunta que anteceda de forma explicativa o que antecede as implantações cartográficas: "A imagem sendo a forma assumida pela estrutura manipulada por um sistema de objetivos intencionais e de ações" (RAFFESTIN, 1993, p. 152).

A linha explicativa vai assumindo, portanto, categorias da representação cartográfica ("Os indivíduos ocupam pontos nos espaços e se distribuem com modelos que podem ser aleatórios, regulares ou concentrados" [RAFFESTIN, 1993, p. 150], ou "[...] toda tessitura implica a noção de limite" [RAFFESTIN, 1993, p. 153]), sem a efetiva clareza sobre o que de fato se representa em um campo relacional de poder.

O que se observa é o modelo analítico-discursivo ganhando corpo em si mesmo, definindo um sistema a partir de um modelo de representação, distanciando-se dos modelos mais complexos que a TGS procurou produzir a partir dos trabalhos de Sotchava. Os modelos, embora busquem uma perspectiva relacional - esta última que deveria debruçar-se sobre materialidades concretas, consolidando o reconhecimento dos elementos ontognosiológicos (FULINO, 2020) -, na verdade, estão presas ao mesmo modelo morfofuncional que o autor buscará distanciar-se:

De fato uma tessitura em vários níveis pode ter por objetivo assegurar para a população o funcionamento no nível ótimo de um conjunto de atividades, ou pode ter por objetivo assegurar o controle da população em nível ótimo (RAFFESTIN, 1993, p. 155).

No excerto acima, por exemplo, está clara sua vinculação com o Estado e o tratamento de antinomias logicistas. Os modelos a que Raffestin está preso, por seus axiomas, nos remetem a compreensão das postulações de Cougo (1997), ao definir que o processo de obtenção de um modelo lógico a partir de um modelo conceitual segue os seguintes passos:

1) Obter o modelo conceitual (no caso o Cartográfico);

2) Definir o tipo de implementação relacional (0-0) (seriam os atores paradigmáticos e sintagmáticos);

3) Aplicar as regras de derivação específicas (sobre os elementos de energia e informação que atuam nas tessituras, nós e redes);

4) Adaptar o modelo às realidades. ("Nesses conjuntos de pontos, que também são localizações e que reagrupam indivíduos ou grupos, se elabora toda existência, quer se trate de aldeias, cidades, capitais ou metrópoles gigantes [RAFFESTIN, 1993, p. 156]).

Para Cougo (1997, p. 7), o "modelo é a representação abstrata e simplificada de um sistema real, com a qual se pode explicar ou testar o seu comportamento, em seu todo ou em partes".

Frente ao que entendemos como limitações epistêmicas e ontológicas de Raffestin, partimos da compreensão de que é necessário estabelecer elementos analíticos, que estejam pautados na realidade concreta, ainda que se coloquem de forma investigativa para em segundo momento expositivas, e que não sejam compreendidos como modelos lógicos e/ou generalizáveis para toda realidade social. Há a necessidade de se considerar a escala e as direções em que os sujeitos (indivíduos, grupos ou instituições públicas e privadas) se organizam e se movimentam sobre o espaço, constituindo seus próprios territórios ${ }^{9}$.

Os espaços agrários, em específico no Brasil, se estabelecem como espaços de disputa entre classes sociais pelo acesso e permanência na terra, como processualidade histórica, na

\footnotetext{
9 "Em graus diversos, em momentos diferentes e em lugares variados, somos todos atores sintagmáticos que produzem 'territórios" (RAFFESTIN, 1993, p. 152).
} 
materialização de uma "teleologia 10 ": da terra ao território, um processo que pode ser orientado à produção de mercadorias e/ou à negação desse modelo de produção.

\section{As práticas socioespaciais: movimentos de constructo e alienação de um território}

Imperativo reafirmar, então, que sempre há poder (trabalho e imediatamente valor) nas práticas socioespaciais e estas sempre colocarão suas ações na direção de projetos societais que poderão se consubstanciar em hegemonia e ou contra hegemonia. A questão central é: qual projeto societal elas constituem (intencionalmente ou não) em sua realização e quais determinações territoriais se materializam nesse processo. O núcleo provedor de poder são as práticas socioespaciais dos sujeitos, o trabalho e as relações sociais estabelecidas, que expressam determinações territoriais na forma de reprodução social, deste núcleo emerge o constructo e ou a alienação territorial. $\mathrm{O}$ trabalho agrícola, como síntese concreta da ação metabólica do homem com o meio e que constitui sua geograficidade (MOREIRA, 2004), é, portanto, definidor da reprodução material da existência humana e seus processos produtivos, são o ponto de partida e simultaneamente de chegada para entender as práticas que negam ou afirmam as territorialidades dos sujeitos sociais.

Nesse exercício de escavação teórica, as práticas socioespaciais foram elencadas considerando nossas vivências de pesquisas com movimentos sociais campesinos, quilombolas e mesmo relativos aos povos originários, por sua vez, estão também lastreados na literatura e compreendemos que ao estabelecermos gradientes, elas se configuram em indicativos da direção que tais práticas assumem, como indicativos de constructos e ou alienação territorial.

\section{Elenco das práticas socioespacias}

A primeira prática socioespacial analisada refere-se à constituição de uma matriz produtiva, uma vez que revela o sentido do trabalho na produção. A dinâmica de produção estabelecida em uma matriz orienta a produção de alimentos ou de mercadorias, definindo a produção em espécie e diversificada sua commoditização. A ordem de grandeza não está, em um primeiro momento, na quantidade, mas na "qualidade" do que se produz (como escolha de uma produção, essa definição tem um profundo caráter ontológico).

A decisão de produção de soja ou de arroz ou de mandioca define e reverbera, de imediato, nas condições de autoconsumo em uma unidade de produção e a isso nos referimos em seu caráter ontológico. Configura-se características de produção de alimento (comida) para si, ou a totalidade de sua produção vinculada aos processos basilares da lógica do valor extraído da terra - que se realiza a partir da produção de commodities - ou produtos agroindustriais do mercado doméstico - produção em si. Polanyi (1980) aponta como de uma posição secundária na vida econômica, os mercados, na economia liberal, passaram a assumir a primazia sobre as relações sociais.

A definição de uma matriz produtiva é condição para a determinação do autoconsumo e/ou efetiva vinculação à lógica de mercados. Em conformidade com Grisa (2007) e Gazolla (2004), o autoconsumo é a parcela produzida pelos agricultores que tenham por destino o consumo próprio de sua família ou do seu grupo social, gerando autonomia na produção, consolidando a soberania alimentar e diminuição no consumo de produtos industrializados. Além dessas consequências imediatas, o autoconsumo pode reconstruir laços sociais, no abastecimento de núcleos rurais e urbanos próximos e adequação de um padrão alimentar e nutricional aos produtos de época (safra) e locais (principalmente sobre as frutas da estação).

Há, nesse sentido, um encadeamento que se remete a um terceiro elemento que compõe o núcleo central: o trabalho familiar. Considerado desde Chayanov (1974), o trabalho familiar é aquele desempenhado pelos membros da família, com divisões sociais de trabalho por idade e gênero e que resultam não apenas na dimensão produtiva, mas nos processos de ocupação familiar, vivência e construção de sociabilidade e aprendizado (PAULILO, 2004).

10 Teleologia compreendida como um processo de consciência de mediação metabólica do sujeito social no mundo. 
Esse conceito permite identificar relações caracterizadas como organização camponesa, demonstrando resistência e oposição ao modelo capitalista moderno de organização, divisão e exploração do trabalho. Entretanto, percebe-se também condições que legitimam uma maior exploração desses agricultores, não apenas pelo mercado, mas pela própria sociedade, como as propostas de pluriatividade (SCHNEIDER, 2003) ou de multifuncionalidade da agricultura familiar, que quer fazer crer, equivocadamente, que a ausência de um real estruturado passa a ser explicativo de mecanismos de ampliação de atividades produtivas para obtenção de renda mínima (CAZELLA; BONNAL; MALUF, 2009; BACCARIN e SOUZA, 2012)11. O fato é que a dimensão do trabalho é reveladora de processos de sucessão familiar na unidade de produção e de processos de produção e de conhecimento técnico produtivo; o que significa a manutenção de conhecimentos de produção, manejo, armazenamento, conservação e processamento alimentar.

O quarto elemento a ser analisado é o consumo intermediário. Como afirmamos anteriormente, a dinâmica de produção estabelecida em uma matriz orienta a produção de alimentos ou de mercadorias, mas também do nível de mercadorias e/ou de inserção de insumo autoproduzidos, produzidos na unidade rural. Em relação direta ao autoconsumo e ao trabalho familiar, o consumo intermediário está tanto nos produtos alimentícios e de uso pessoal (roupas, remédios, calçados, estéticos, culturais) como em produtos para a produção agrícola em si (como o uso de modelos de produção dependentes de uma escala de produtos técnicos para que a produção ocorra, ou de técnicas de separação de sementes, produção de enxertos, compostagens, entre outros).

O consumo intermediário é um elemento qualitativo e quantitativo, uma medida que estabelece relação direta entre quantidade de produtos adquiridos nos mercados para consumo em relação ao que teve origem na unidade agrícola de produção. Como exemplo, a diminuição da autoprodução de insumos indica um grau de dependência mercantil da agricultura camponesa, já que quanto maior o consumo intermediário, menor é a autonomia produtiva (GAZOLLA, 2006). O consumo intermediário também é a medida da alienação econômica do trabalho e expressa, ainda, relação de poder, pois identifica a capacidade de extração da renda da terra e perda de autonomia e domínio técnicoprodutivo, o que resulta ainda na subsunção formal do trabalho camponês ao capital (MARX, 1985), em específico de extorsão de sobre-trabalho, que se estabelece nas duas pontas: na compra de insumos e, portanto, transfere renda; e no limite, na circulação, com os atravessadores, quando também transfere renda pela forma de remuneração de seu produto-trabalho e se insere na dimensão de financeirização se esse processo é mediado pelo crédito (os fundos públicos).

Desse modo, o consumo intermediário pode representar em uma lógica produtiva intensiva, mesmo em assentamentos rurais, não apenas à produção em si de mercadorias, mas uma dimensão mais concreta de uso extenuado de elementos produtivos (terra e água, por exemplo) reduzindo os níveis de preservação e de relação direta com natureza, o que implica em qualidade de vida e de manutenção da vida e de "bens comuns"(SOUZA, 2018).

Esta lógica de produção como prática socioespacial resulta em considerar uma ruptura metabólica do homem com a natureza, consigo mesmo e na relação com os outros homens. Esta fratura metabólica destacada por Foster (2010), com base em Marx (1985), ao tratar da desconexão ou o desequilíbrio da interação metabólica entre a humanidade e o resto da natureza, decorre, nesse sentido, da centralidade da mercadoria, da mercantilização da natureza, como forma unilateral de relação metabólica societal. Assim, as práticas de uma agricultura de morte, centrada nos agrotóxicos, revela mais do que uma dimensão produtiva, mas também um grau de alienação do trabalho, da terra e da vida e, então, uma alienação territorial.

Outros dois elementos a considerar são: circuito curto e circuito longo de comercialização. Aos circuitos curtos, observam-se propostas comerciais de aproximação entre consumidor e produtos (VEIGAS, 2016); quanto mais fortalecido for o circuito curto, maiores serão os laços e relações entre esses dois sujeitos, além da resistência ao padrão industrial de produção e venda (RETIĖRE, 2014). Estas resistências são ancoradas no autoconsumo, considerando ainda que na cadeia de valor há uma redução de extração de renda da terra e (tendencialmente) uma direção de preços mais

11 Para Bonnal e Maluf (2007), a discussão sobre a multifuncionalidade da agricultura foi inserida de forma oportunista nas negociações internacionais da Organização Mundial do Comércio (OMC), distanciando-se das demandas centrais de equilíbrio e manutenção das comunidades agrícolas. 
acessíveis aos consumidores. Já os circuitos longos caracterizam-se pela homogeneidade dos produtos - tendência à commoditizacão da agricultura, conforme Souza e Cabero Diegues (2012) -, interferência econômica nos preços e distanciamento entre consumidor e produtor, aumento de transferência da renda da terra e consolidação de uma cadeia de valor que tende a aumentar fortemente os preços e o padrão de acumulação.

A conservação ambiental é outro elemento a ser considerado no núcleo central. Acredita-se que não exista uma separação, em nenhum momento, entre os sujeitos e o meio natural. Indicar a forma como essa relação existe pode demonstrar o nível de exploração dos sujeitos sobre os bens comuns, o nível de mercantilização da natureza e de seu esgotamento produtivo, sem considerar os processos de contaminação da água, do solo e dos produtos. Assim, a reconversão produtiva agroecológica amplia as relações de um ambiente social e rompe com o dualismo campo cidade, além de estabelecer formas de relação produção consumo que não se sintetizam na troca, mas em outras dimensões que se incorporam elementos sociais e culturais mais amplos. A agroecologia, ou agricultura agroecológica, passa a contemplar a reordenação das formas de produção com base na diversidade, construindo referências à fertilidade do solo, à preservação de outros recursos naturais e ao respeito aos valores culturais locais, passando pelo uso de sistemas não convencionais de produção e pela diversificação de atividades agrícolas na propriedade (CARNEIRO, MALUF, 2003).

Os dois últimos elementos considerados para a construção do núcleo de poder são: qualidade de vida e patrimônio histórico e cultural. Ao primeiro, consideramos a capacidade explicativa que os índices possuem tanto nas análises populacionais, como em aspectos econômicos, ambientais, sociais e de saúde (CARNEIRO e MALUF, 2003; KLUTHCOVSKY e TAKAYANAGUI, 2007). Já o elemento patrimônio histórico e cultural recai sobre as práticas culturais, religiosas, técnicas de trabalho e de alimentação (COSTA, 2017) que, ao seu reconhecimento, é possível observar o nível de homogeneização de técnicas e de modo de vida, por exemplo, indicando a dependência de uma cultura imposta pelo modelo capitalista urbano ou de resistência a ele.

Para Costa (2017, p. 56):

Os vínculos sociais identitários com o território envolvem a realização da vida em diferentes escalas e específicos grupos, ou seja, a experiência espacial do sujeito. A geografia histórica da América Latina revela tais vínculos, em períodos longos ou curtos e no cerne de regiões e de territórios definidos pela instituição discursiva de direitos e de deveres, que são concretizados, distintivamente, com o atendimento irrestrito às demandas do trabalho. Logo, o que se define por patrimônio-territorial latinoamericano tem, na sua essência, a lógica histórica da interação sociedade-natureza, com o enaltecimento de problemáticas existenciais indígenas e negras (na violência de gênero, de etnias, de cultura, de identidade, de religião, de localização etc.); realizou-se na produção de 'territórios de exceção', dadas as especificidades continentais da divisão social e espacial do trabalho.

A natureza desses elementos não se inscreve de forma binária, sobre a dualidade de existência e não existência, presença e não presença, porque a realidade não se inscreve como todo, mas como totalidade e, neste sentido, a impossibilidade de apreendê-la, exige considerar suas determinações mais profundas e concretas, bem como seus movimentos histórico-dialéticos que resultam em uma análise e compreensão da realidade. Como adverte Konder (2009, p. 39) "o real, na infinita riqueza de seu movimento, é irredutível à consciência como um todo, de modo que a identidade sujeito-objeto nunca poderá ser total e definitiva". O elenco de tais práticas foi aleatório e podem ser excluídas ou receber mais elementos, a fim de especificação em busca da compreensão da realidade.

A análise do desenvolvimento de tais práticas tende a revelar se há, nos territórios analisados, um constructo ou uma alienação territorial que se inscreve a partir das práticas socioespaciais exercidas, tais perspectivas existem a partir de uma condição primeva nas análises sobre o espaço rural brasileiro: a renda da terra. Por ela, entende-se que é "[...]o lucro extraordinário, permanente...que ocorre tanto no campo como na cidade. O lucro extraordinário é a fração apropriada pelo capitalista acima do lucro médio. [...] na agricultura ele é permanente, pois, por exemplo, existem diferenças entre fertilidade natural dos vários tipos de solos" (OLIVEIRA, 2007, p. 43). É por meio desta condição de acumulação, por parte daqueles que habitam e atuam sobre o espaço agrário, que será possível entender como as relações de poder se mantêm. 
Figura 1 - Práticas Socioespaciais

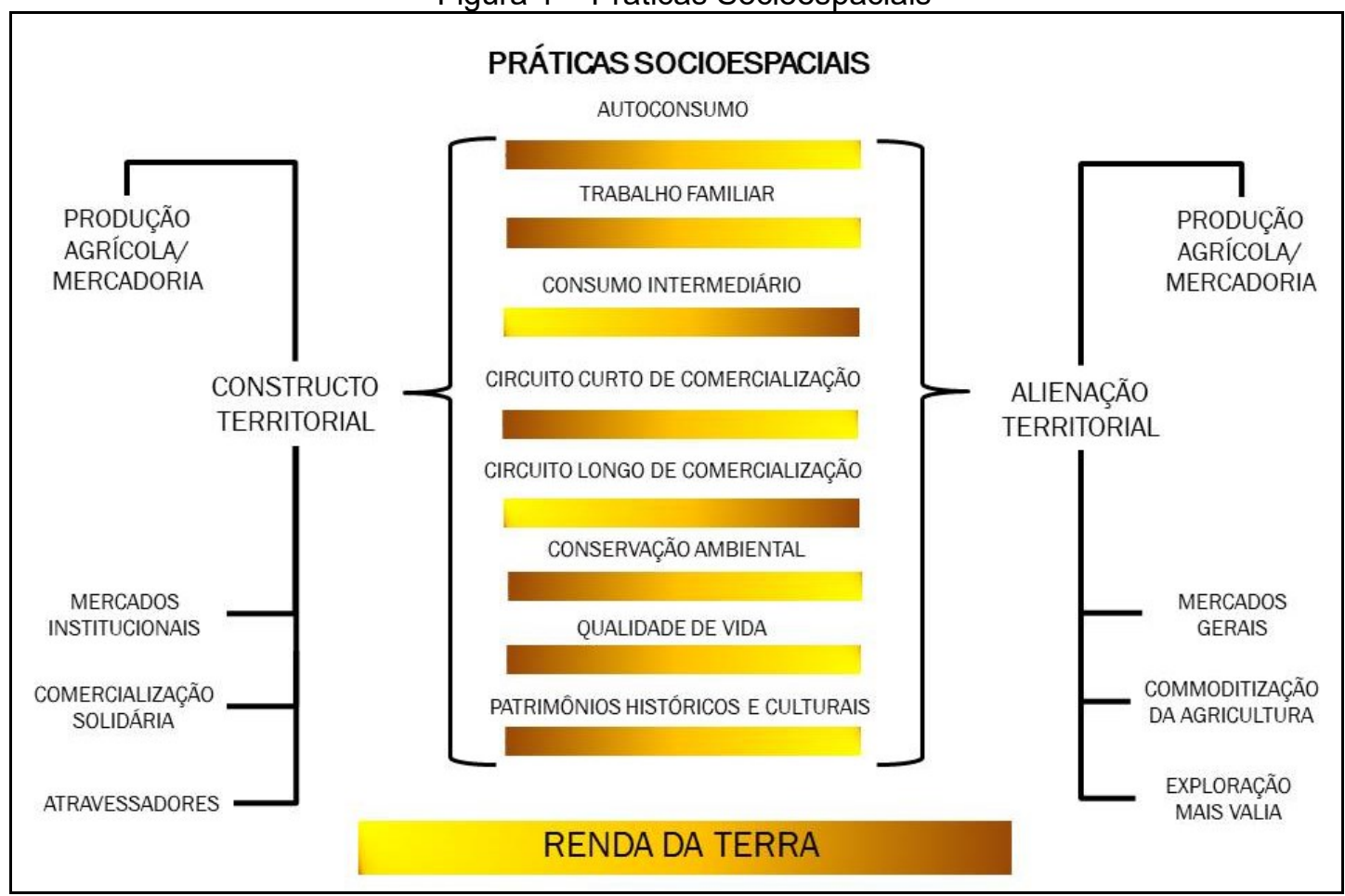

Fonte: BERTOLIN e SOUZA (2020)

Estes elementos teóricos que resultam no movimento-momento metodológico de investigação são explicativos de práticas socioespaciais que concorrem com determinações territoriais que podem estabelecer o assentamento como um núcleo provedor de poder relacional de transformação de seu recorte territorial e de outros territórios e territorialidades (SILVA, 2013).

Essas determinações territoriais partem, portanto, das esferas sociais (a), econômicas (b), culturais (c) e ambientais (d) e não se estabelecem de forma monolítica, apresentam variabilidades, nuances, em uma mesma unidade produtiva. É nesse sentido que chamamos a atenção para o nível de força e de potência, que gradativamente manifesta o nível de autonomia e dependência dos sujeitos sociais e como interferem tais dinâmicas territoriais no nível de força e potência das outras práticas socioespaciais, considerando a imbricação que elas apresentam, o que determina o constructo e ou a alienação territorial.

Todas essas determinações podem e devem sofrer alterações (seja pelo aprofundamento ou pela sua ausência), uma vez que se busca a compreensão dos elementos que se configuram por existirem em decorrência das relações assimétricas de poder. Portanto, a depender de cada recorte espacial definido (sua localização, tamanho, configuração, grupos e expressão), novas determinações se apresentam e devem ser agregadas e outras, suprimidas. Ressalva-se que esse é apenas um momento do método dialético explicitado por Marx, em que a realidade dá forma e sistematização (exposição) na análise dos espaços agrários. Justamente por terem o conflito entre classes como característica principal, não podem ser contemplados em análises que não considere tais negações e dialeticidade.

Debruçar-se sobre a realidade dos assentamentos rurais, especificando cada lote com sua respectiva gradação, permitirá observar a complexidade das relações conflituosas de classe nas quais as famílias estão inseridas, tendo que a sobreposição dessas relações constituem o assentamento rural, resultando na identificação das relações de poder, no grau de alienação ou de constructo desses territórios, respectivamente. 


\section{CONSIDERAÇÕES FINAIS}

Por coerência do método é importante destacar que é a realidade quem informa a análise, e não as categorias elencadas pelo pesquisador que são postas e/ou justapostas ao real. Sujeitos emancipados percebem as condições de exploração nas quais estão inseridos. Dessa forma, buscase a soberania de sua família e do coletivo, quebrando o ciclo de exploração e mudando a lógica de ocupação e exploração dos bens comuns. Destaca-se ainda que não há uma hierarquia e um ponto de partida analítico nesses elementos e práticas socioespaciais, qualquer uma delas pode ser suficientemente capaz de iniciar e consolidar análises acerca do constructo territorial. Cabe ao pesquisador ter clareza metodológica acerca do grau de importância e capacidade explicativa destas categorias, o que rompe qualquer possibilidade de se estabelecer um sistema.

Algumas problemáticas foram encontradas no exercício de investigação das considerações de Raffestin (1993) sobre um sistema territorial. A primeira contradição recai sobre a não continuidade no uso do método proposto inicialmente pelo autor, até as representações feitas por ele. A dedicação por uma lógica quase geométrica ao buscar representar as relações de poder fizeram com que Raffestin abandonasse a exposição das contradições e entendesse apenas as estruturas ou condições finais das relações sociais capitalistas. Ao buscar essa representação a todo custo, o autor faz uso de instrumentos cartesianos e matemáticos, tendo nos axiomas o ponto de partida para as análises, o que foi considerado como um desacordo com a proposta inicial de análise relacional; principalmente pelo fato de serem constituídas a partir das relações de poder entre os sujeitos e dos sujeitos com o espaço e esse processo é concreto e não abstrato. É nessa tentativa de busca por uma logicidade que o autor não perscruta os elementos (determinações) centrais o objeto-processo estudado. Nessas condições, elencar elementos que sejam parte das práticas socioespaciais de nosso espaço agrário mostra-se como fundamental para entender as relações de poder que ali se assentam.

Consideramos que, apenas a partir das ponderações elencadas, voltadas principalmente ao entendimento das relações de poder, é possível observar sua expressão nos territórios agrários. A perspectiva metodológica materialista reforça a necessidade de entendimento de todas as determinações territoriais que decorrem das práticas socioespaciais dos sujeitos, evidenciando seus núcleos e graus de emancipação desses sujeitos sociais do campo; para então buscar uma representação de tais práticas.

Por fim, cabe considerar que as determinações territoriais esboçam uma centralidade, e ela se remete à renda da terra. $\mathrm{O}$ dinamismo das práticas socioespaciais dos sujeitos revela não apenas a lógica da mercadoria que se coloca na extração da produção quando tais práticas colocam o trabalho em uma mimetização da renda, do lucro e do mercado. Parece-nos que a perspectiva sistêmica representa essa lógica ensimesmada, sem saída, como se fossem atores paradigmáticos atuando sob a lógica circunscrita pelo agronegócio. Esta mimetização representa seus efeitos na alienação e que se desdobra sobre inúmeras determinações, as mais singulares são a própria terra-território e o sujeito social como mercadorias, e seu lugar de vivência não como espaço de reprodução de uma existência livre, autônoma e solidária, mas subordinada e alienada.

\section{AGRADECIMENTOS}

Agradecemos ao CNPq pelo financiamento e ao CEAPLA/IGCE/UNESP Rio Claro pelo laboratório.

\section{REFERÊNCIAS}

ALVES, William Rosa; SOUZA, José Gilberto de. A Geografia e o Materialismo Histórico Dialético. Terra Livre, v. 1, n. 54, p. 923- 961, jan.-jun./2020.

ALVES, A. R. C. O conceito de hegemonia: de Gramsci a Laclau e Mouffe. Revista Lua Nova, São Paulo, 80: 71-96, 2010. https://doi.org/10.1590/S0102-64452010000200004

ARCASSE, W. S. A natureza da Geografia em Richard Hartshorne. Londrina:UEL, 2018 (Tese de Doutorado). 
BACCARIN, J.G., SOUZA, J.G. Um questionamento sobre a capacidade explicativa do conceito de pluriatividade. em uma região de pequena agricultura diversificada. Geografia. v. 37. n. 1, p.19-31, 2012..

BECKER, B. K. O uso político do território: questões a partir de uma visão do terceiro mundo. In: BECKER, B. K. et al. Abordagens políticas da espacialidade. (org. Becker, B. K.; Haesbaert, R.; Silveira, C. B.) Universidade Federal do Rio de Janeiro. RJ, 1983.

BERTALANFFY, Luwing von Teoria Geral dos Sistemas. Tradução de Francisco M. Guimarães. Petrópolis: Vozes, 1973.

BORGES, A. C. G. ; SOUZA, J.G. . Território financeirizado: as determinações territoriais dos desembolsos do BNDES ao setor sucroenergético no Mato Grosso e Mato Grosso do Sul - Brasil. Confins (Paris), v. 1, p. 17223-17263, 2019. https://doi.org/10.4000/confins.17223

CARNEIRO, Maria José e MALUF, Roberto $S$. Introdução. In: CARNEIRO, Maria José e MALUF, Roberto S. (Orgs.) Para além da produção: multifuncionalidade e agricultura familiar. Rio de Janeiro: Mauad, 2003. p. 17-27.

CASTRO, I. E. de Geografia e Política: território, escalas de ação e instituições. 2. ed. Rio de Janeiro: Bertrand Brasil, 2009.

CAZELLA, Ademir A.; BONNAL, Philippe; MALUF, Renato S. Agricultura Familiar: multifuncionalidade e desenvolvimento territorial no Brasil. Rio de Janeiro: MAUAD X, 2009.

CHAYANOV, A. V. La organizacion de la unidad economica campesina. Tradução de Rosa Maria Russovich. Buenos Aires: Nueva Vision, 1974.

CHRISTOFOLETTI, Antônio Análise de Sistemas em Geografia. SP: HUCITEC, Editora da USP, 1979.

COSTA, E. B. Ativação popular do patrimônio-territorial na América Latina: teoria e metodologia. Cuadernos de Geografía: Revista Colombiana de Geografía, 26 (2) 2017: 53-75. https://doi.org/10.15446/rcdg.v26n2.59225

COUGO, P. Modelagem conceitual e projeto de banco de dados. Rio de Janeiro: Ed. Campus, 1997.

FERNANDES, B. M. Movimentos socioterritoriais e movimentos socioespaciais. Observatório Social de América Latina. vol. 16, 2005, p. 273-284.

FOSTER, J. B. A ecologia de Marx: materialismo e natureza. Rio de Janeiro: Civilização Brasileira, 2010.

FULINO, R. A "geografia do poder" de Claude Raffestin. Uma contribuição à teoria materialista do território. Rio Claro:IGCE/Unesp, 2020.(Tese de Doutorado).

GAZOLLA, M. Agricultura familiar, segurança alimentar e política pública: uma análise a partir da produção para autoconsumo no território do Alto Uruguai/RS. Dissertação de Mestrado. Universidade Federal do Rio Grande do Sul/ FCE/ PGDR. Porto Alegre, 2004.

GAZOLLA, M. O processo de mercantilização do consumo de alimentos na agricultura familiar. In: SCHENIDER, Sergio. A diversidade da agricultura familiar. Porto Alegre: Editora da UFRGS, 2006.

GRISA, Cátia Para além da alimentação: papéis e significados da produção para autoconsumo na agricultura familiar. Revista Extensão Rural, DEAER/CPGExR - CCR/ UFSM, ano IV, jan/dez, 2007.

KLUTHCOVSKY, Ana C. G. C.; TAKAYANAGUI, Angela M. M. Qualidade de vida: aspectos conceituais. Revista Salus - Guarapuava- PR. Jan-jun, 2007.

KONDER, L. Marxismo e alienação. Rio de Janeiro: Civilização Brasileira, 2009.

KOSIK, K. Dialética do Concreto. Rio de Janeiro: Ed. Paz e Terra, 1969.

LUKÁCS, G. Ontologia do ser social. Os princípios ontológicos fundamentais de Marx. Tradução de Carlos Nelson Coutinho. São Paulo: Livraria Ciências Humanas, 1979. 
MARX, K O Capital (Crítica da Economia Política) - Livro 1: o processo de produção do capital. v. 1. 5. ed. Tradução de Reginaldo Sant'anna. Coleção Perspectivas do Homem, v. 38, série economia. Rio de Janeiro: Editora Civilização Brasileira, 1980.

MARX, K. Capítulo VI Inédito de 0 Capital: Resultado do Processo de Produção Imediato. São Paulo: Editora Moraes, 1985.

MARX, K. Crítica da filosofia do direito de Hegel. São Paulo : Boitempo, 2010 .

MARX, K.; ENGELS, F. A ideologia alemã. Trad. M. Backes. Rio de Janeiro: Civilização Brasileira, 2007.

MORAES, A. C. R. Geografia: pequena história crítica. 21. ed. São Paulo: Annablume, 2007.

MOREIRA, R. Marxismo e Geografia (A Geograficidade e o diálogo das Ontologias). GEOgraphia Ano. 6 - n. 11 - 2004. p. 21-37. https://doi.org/10.22409/GEOgraphia2004.611.a13466

MOSCOVISK, S. Representações Sociais: Investigações em Psicologia Social. Tradução: Pedrinho. A. Guareschi. 7. Ed. - Petrópolis, RJ: Vozes, 2010.

MÜLLER, M. L. Exposição e Método Dialético em "O Capital". In: Marx. Boletim SEAF-MG, v. 2. Belo Horizonte, 1983, p.17-41.

NEVES, C. E.; MACHADO, G.; HIRATA, C.A.; STIPP, N. A. F. A importância dos geossistemas na pesquisa geográfica: uma análise a partir da correlação com o ecossistema. Revista Soc. \& Nat., Uberlândia, 26 (2): 271-285, mai/ago/2014. https://doi.org/10.1590/1982-451320140206

OLIVEIRA, A. U. de Prefácio em FERNANDES, B. M. MST movimento dos trabalhadores rurais sem-terra: formação e territorializaçao em São Paulo. SP: Hucitec, 1996.

OLIVEIRA, A. U. Modo de Produção Capitalista, Agricultura e Reforma Agrária. São Paulo: FFLCH, 2007.

PAULILO, Maria I. S. Trabalho Familiar: uma categoria esquecida de análise. Estudos Feministas, Florianópolis, 12 (1): 360, janeiro-abril, 2004. https://doi.org/10.1590/S0104-026X2004000100012

POLANYI, K. A grande transformação: as origens da nossa época. Rio de Janeiro, Campus, 1980.

QUAINI, M. A construção da Geografia Humana. Rio de Janeiro: Paz e Terra, 1979.

RAFFESTIN, C. Por uma Geografia do poder. Traduzido por Maria Cecília França. São Paulo: Editora Ática, 1993.

RATZEL, F. O solo, a sociedade e o Estado. Geousp - Revista do Departamento de Geografia, v. 2, p. 93-101, 2011. https://doi.org/10.7154/RDG.1983.0002.0008

RETIĖRE, Morgane I. H. Agricultores inseridos em circuitos curtos de comercialização: modalidades de venda e adaptações dos sistemas agrícolas. Dissertação de Mestrado. Universidade de São Paulo/ESALQ/CENA, Piracicaba, 2014.

SARTRE, J.P. Crítica da Razão dialética. São Paulo: DP \& A Editora, 2002.

SCHNEIDER, Sérgio Teoria social, agricultura familiar e pluriatividade. Revista Brasileira de Ciências Sociais - v. 18, n. 51, 2003. https://doi.org/10.1590/S0102-69092003000100008

SILVA, M. E. S. A Representação Social e Territorialização da Reforma Agrária no Espaço Urbano a Partir do Programa de Aquisição de Alimentos. Rio Claro: UNESP, 2013. (Dissertação Mestrado em Geografia)

SOBREIRO FILHO, J. Movimentos socioespaciais, socioterritoriais, manifestações e as redes sociais: das manifestações internacionais ao Movimento Passe Livre-SP. GeoGraphos. [En línea]. Alicante: Grupo Interdisciplinario de Estudios Críticos y de América Latina (GIECRYAL) de la Universidad de Alicante, 6 de enero de 2015, v. 6, n. 73, p. 1-29. https://doi.org/10.14198/GEOGRA2015.6.73

SOJA, E. W. The political organization of space. Washington D.C., Association of American Geographers, 1971. 
SOTCHAVA, V. B. O estudo de geossistema. Traduzido do inglês por Carlos Augusto Figueiredo Monteiro e Dora de Amarante Romaria, com autorização do autor. Série Métodos em questão, IGEOG, USP, n. 16, 1977.

SOUZA, J.G. CABERO DIEGUES, V. Por uma desglobalização da produção alimentar: commoditização da agricultura e diversidade produtiva - uma análise de Espanha. GEOgraphia (UFF), v. 14, p. 63-81, 2012. https://doi.org/10.22409/GEOgraphia2012.1428.a13643

SOUZA, J.G. Estado, Crise Estrutural do Capital e a Questão Agrária. XXIV ENGA, Dourados MS. 2018 - (Digit.).

SOUZA, J.G. Limites do território. Agrária (São Paulo. Online), v. 10, p. 99-130, 2009. https://doi.org/10.11606/issn.1808-1150.v0i10-11p99-130

SOUZA, J.G. Local-Global: território, finanças e acumulação na agricultura. In: LAMOSO, L.P. (Org.) Temas do desenvolvimento econômico brasileiro e suas articulações com o Mato Grosso do Sul. 1ed.Curitiba-PR: Íthala, 2016, v. 1, p. 26-54.

SOUZA, J.G. Determinantes do processo histórico do trabalho rural no Brasil. In: Campanha Nacional de Prevenção de Acidentes do Trabalho na Área Rural, 2001, Campo Grande - MS. Anais do Seminário de Lançamento da CANPATR 2001. Campo Grande - MS: Delegacia Regional do Trabalho - MS - MTE., 2001. v. 1. p. 11-30.

SOUZA, J.G., KATUTA, A.M. Geografia e Conhecimentos Cartográficos: a Cartografia no movimento de renovação da Geografia brasileira e a importância do uso de mapas. 1. ed. São Paulo: Editora da UNESP, 2001. v. 1. 162p .

SOUZA, J.G. A Questão Indígena: Acumulação por Espoliação e Monopolização do Território (A economia política do agronegócio). Prim@ Facie, v. 12, p. 1-42, 2014.

TROPPMAIR, H. Geossistemas e geossistemas paulistas. Rio Claro, 2000.

VEIGAS, M. T. Agroecologia e circuitos curtos de comercialização num contexto de comercialização da agricultura orgânica. Dissertação de Mestrado. Universidade Federal de Santa Catarina/CCA/ProgPGA. Florianópolis, SC, 2016.

Recebido em: 20/09/2020

Aceito para publicação em: 17/11/2020 